\title{
Study of a prototypical convective boundary layer observed during BLLAST: contributions by large-scale forcings
}

\author{
H. P. Pietersen ${ }^{1}$, J. Vilà-Guerau de Arellano ${ }^{1}$, P. Augustin ${ }^{2}$, A. van de Boer ${ }^{1}$, O. de Coster ${ }^{1}$, H. Delbarre ${ }^{2}$, P. Durand ${ }^{3}$, \\ M. Fourmentin ${ }^{2}$, B. Gioli ${ }^{4}$, O. Hartogensis ${ }^{1}$, F. Lohou ${ }^{3}$, M. Lothon ${ }^{3}$, H. G. Ouwersloot ${ }^{5}$, D. Pino ${ }^{6}$, and J. Reuder \\ ${ }^{1}$ Meteorology and Air Quality Section, Wageningen University, Wageningen, the Netherlands \\ ${ }^{2}$ Laboratoire de Physico-Chimie de l'Atmosphère CNRS, Université du Littoral Cote d'Opale Dunkerque, France \\ ${ }^{3}$ Laboratoire d'Aérologie, Université de Toulouse and CNRS, Lannemazan, France \\ ${ }^{4}$ Institute of Biometeorology, IBIMET CNR, Florence, Italy \\ ${ }^{5}$ Atmospheric Chemistry, Max-Planck Institute for Chemistry, Mainz, Germany \\ ${ }^{6}$ Department of Applied Physics, Universitat Politècnica de Catalunya, BarcelonaTech, \\ and Institute for Space Studies of Catalonia (IEEC-UPC), Barcelona, Spain \\ ${ }^{7}$ Geophysical Institute, University of Bergen, Bergen, Norway \\ Correspondence to: J. Vilà-Guerau de Arellano (jordi.vila@wur.nl)
}

Received: 27 June 2014 - Published in Atmos. Chem. Phys. Discuss.: 23 July 2014

Revised: 22 March 2015 - Accepted: 7 April 2015 - Published: 24 April 2015

\begin{abstract}
We study the influence of the large-scale atmospheric contribution to the dynamics of the convective boundary layer (CBL) in a situation observed during the Boundary Layer Late Afternoon and Sunset Turbulence (BLLAST) field campaign. We employ two modeling approaches, the mixed-layer theory and large-eddy simulation (LES), with a complete data set of surface and upper-air atmospheric observations, to quantify the contributions of the advection of heat and moisture, and subsidence. We find that by only taking surface and entrainment fluxes into account, the boundary-layer height is overestimated by $70 \%$. Constrained by surface and upper-air observations, we infer the large-scale vertical motions and horizontal advection of heat and moisture. Our findings show that subsidence has a clear diurnal pattern. Supported by the presence of a nearby mountain range, this pattern suggests that not only synoptic scales exert their influence on the boundary layer, but also mesoscale circulations. LES results show a satisfactory correspondence of the vertical structure of turbulent variables with observations. We also find that when large-scale advection and subsidence are included in the simulation, the values for turbulent kinetic energy are lower than without these large-scale forcings. We conclude that the prototypical $\mathrm{CBL}$ is a valid representation of the boundary-layer dynam-
\end{abstract}

ics near regions characterized by complex topography and small-scale surface heterogeneity, provided that surface- and large-scale forcings are representative for the local boundary layer.

\section{Introduction}

The daytime convective boundary layer is essentially governed by heating at the surface and the conditions of the free troposphere. The surface heating causes warm air to rise to the top of the boundary layer in the form of coherent turbulent structures and to entrain air from aloft. As a consequence, the convective boundary layer (CBL) grows and becomes warmer and drier (Stull, 2000). Without the presence of clouds, the surface heating is driven by the diurnal solar cycle and it is the dominant contribution to the CBL dynamics. This CBL development can be influenced by the vertical and horizontal advection of heat, momentum and moisture within and above the CBL. In the late afternoon, when the incoming short wave radiation begins to decrease, the growth of the boundary layer slows down and the convective boundary layer reaches a quasi-steady state, due to the offsetting effects of surface fluxes and subsidence, with the greatest depth 
at the end of the afternoon. This conceptualization of the boundary-layer structure and evolution is referred to herein as the prototypical boundary layer.

To study this canonical CBL, one assumes that the main drivers are the turbulent fluxes at the surface and at the entrainment zone, whereas the large scale forcing are prescribed as done by Lilly (1968) in his pioneer study of marine stratocumulus. This local CBL can be influenced by these large scale motions such as subsidence and advection as shown in Fig. 1, in which the local boundary layer is marked by the dashed box. Consequently, to take these motions in modeling the CBL into account, we need to have a reliable estimation of the values and evolution of these large-scale forcings. Over land, several studies have been conducted including large scale forcings, influencing the development of the boundary layer dynamics (for example, Basu et al., 2008; Kumar et al., 2010; Edwards et al., 2014). Closely connected to our study, due to the similarities of steep topography features near the observational site, in a study of boundary layer development, De Wekker (2008) showed that the heat budget is modified near a mountain slope, not only within the CBL, but also aloft. As a result, CBL growth is suppressed. The role of subsidence has been investigated more often in marine boundary layers, in which it exerts a strong influence on the formation and dissipation of boundary-layer clouds (Lilly, 1968; Stevens et al., 2005).

Large-scale forcing, values and evolution, are normally supplied by three-dimensional large-scale models like the European Centre for Medium-range Forecasting (ECMWF) model, or indirectly by the analysis of upper air observations (e.g. radiosounding) like the temporal evolution of the potential temperature free tropospheric lapse rate. Here, we propose a method to retrieve the values of large scale motions that influence the formation and development of the local boundary layer in the proximity of the large mountain range of the Pyrenees. Our method is based on using mixedlayer theory applied to the budgets of heat and moisture (Lilly, 1968; Tennekes and Driedonks, 1981) constrained with a comprehensive data set gathered during the Boundary Layer Late Afternoon and Sunset Turbulence (BLLAST) experiment (Lothon et al., 2014). Our working hypothesis is that large scale forcings can be inferred by combining these mixed-layer model results guided by the completeness of surface and upper-air boundary layer observations gathered during BLLAST field campaign. The main advantage of this method is that it is inherently representative for the local boundary layer and does not require a complex modeling effort using three-dimensional models. To complete the study, we further investigate whether the turbulent characteristics of this prototypical CBL are influenced by the large-scale forcings. This latter study is based on large-eddy simulation experiments using identical surface boundary conditions and early-morning initial conditions as in the mixed-layer experiments.
This paper will first introduce the BLLAST experiment and provide a brief overview of the observations in Sect. 3, including a detailed analysis of the study case, from synoptic to local spatial scales. Special attention is given to the selection criteria for the case and the large scale conditions during this day. Section 4 describes the set-up of the numerical experiment and introduces the models that are used. In Sects. 5 and 6, the results of the numerical experiment are compared to the observations with special attention on the evolution in time and the vertical structure of the boundary layer and a discussion on the estimations of the large scale forcing. Finally, conclusions are drawn, followed by recommendations for future research.

\section{The BLLAST experiment}

The Boundary Layer Late Afternoon and Sunset Turbulence (BLLAST) experiment (Lothon et al., 2014) seeks to study the transition between the convective and stable boundary layer, when a stable boundary layer (SBL) forms above the surface and the turbulence inside the daytime boundary layer slowly decays (Garratt and Brost, 1981; Sorbjan, 1997), leaving a residual layer above the SBL. During this campaign the surface conditions, the boundary-layer properties and the lower atmosphere were extensively monitored in space and time near Campistrous, France, approximately $40 \mathrm{~km}$ north of the central range of the Pyrenees mountains. This site was located on a plateau at a height of $600 \mathrm{~m}$ a.s.l. at the foot of the Pyrenees mountain range with heights of approximately $2000-2500 \mathrm{~m}$. The BLLAST campaign provides us with a continuous and comprehensive observational data set of surface- and boundary-layer observations, supplemented with data from 11 intensive observations periods (IOPs) that took place during June and July 2011. During several IOPs of this campaign, large scale motions were suspected to influence the boundary layer (Lothon et al., 2014). Whilst the main focus was on measuring the boundary-layer properties, attention was also paid to surface measurements, especially because the campaign took place in an area characterized by large surface heterogeneity. To characterize the synoptic conditions, the entire troposphere was monitored extensively. Together, all these observations create a high quality data set, combining up to eight methods to estimate the boundarylayer height. Using all surface data and boundary-layer observations, this data set gives a unique opportunity to carry out a detailed study of the local atmospheric boundary layer influenced by heterogeneous surface conditions and the proximity of complex topography. Most of the instruments were operating continuously, but there were several platforms that operated intermittently. Among these were tethered balloons, manned and unmanned aircraft and radiosoundings. The operation of these platforms was limited to weather situations characterized by weak synoptic patterns to better study the 


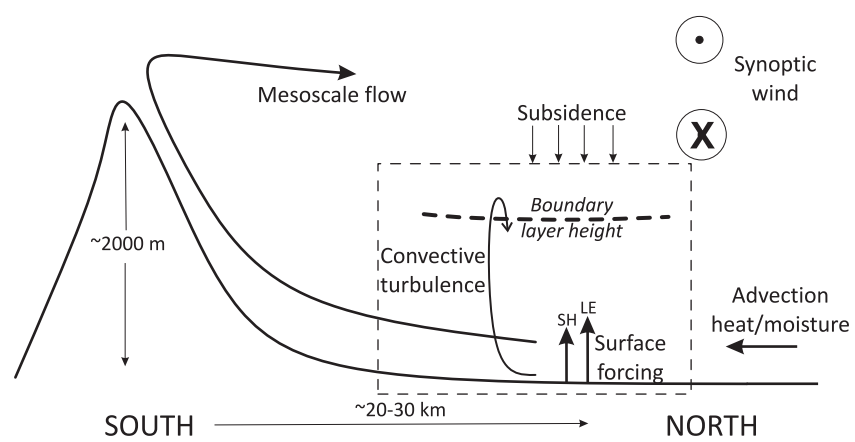

Figure 1. Sketch of the main process driving the development of the atmospheric boundary layer observed on 25 June 2011 (IOP5). The majority of the surface stations were located near the main site (see Fig. 4), whereas the aircraft measurements were gathered in an east-west direction during the case under study. Note that the shear produced by the opposite wind direction is occurring above the boundary layer $(\sim 600 \mathrm{~m})$ as shown at Fig. 3 .

combined effects of CBL dynamics, mesoscale and synoptic scales.

These periods of intensive observation (IOP) included the clearest and least disturbed days of the campaign. However, due to logistics and instrumental performance, not all platforms operated simultaneously all the time. Therefore, there were differences in instrumental availability between different IOPs.

\section{Observational description of the representative boundary layer}

First we set up criteria to select which IOP of BLLAST to study. After that we describe the meso- and synoptic situation in detail and the evolution of the energy exchange at the surface during this day. As an overview of the case analyzed in this research, we summarize at Fig. 1 the main processes that are quantified and discussed.

\subsection{Case selection}

Our aim is to investigate whether the prototype CBL (Stull, 2000) is a useful concept to be applied in regions characterized by large surface heterogeneity and mesoscale phenomena driven by topography. The analysis of the data is supported by the use of a conceptual model that enables us to quantify the individual contributions to the heat, moisture and momentum budgets. More detailed numerical experiments are made with a large-eddy simulation that allow us to study the turbulent structure and its evolution.

From the 11 IOPs, we define a set of criteria to select the most representative IOP period to study the deviations from the CBL prototype due to the large-scale forcing. These criteria are as follows.

1. The instrumental availability should be high.
2. The day should be free of clouds in order to obtain an evolution of radiation and subsequent surface fluxes that are more optimal for the assumptions of the conceptual model.

3. Large scale forcings should be present, but these should only lead to relatively minor variations during the day. For instance, passing fronts will drastically change the weather conditions and thus the growth of the CBL, and are therefore excluded.

4. The vertical structure of heat and humidity should evolve gradually. Layers which enhance or inhibit boundary layer growth (e.g. inversions, shear zones or a residual layer) would influence the strength of entrainment and as a result, the boundary-layer properties (Stensrud, 1993; Conzemius and Fedorovich, 2008).

IOP5 satisfies the criteria stated above the best.

In the next sections, this day will be described in more detail.

\subsection{Case description: large scale forcings}

Here we describe the main synoptic and mesoscale features occurring during IOP5. Since it is difficult to distinguish the specific contributions of the meso- and synoptic scales from a local boundary-layer perspective, we group them under the name large-scale forcings. In Fig. 2, the geopotential height at $500 \mathrm{hPa}$ and the pressure distribution at the surface, using the European Centre Medium Weather Forecast (ECMWF) reanalysis model, is shown for 25 June 2011 at 12:00 UTC. The red dot shows the location of the BLLAST experiment. During this day, a large system of high surface pressure is located over central France and the Alps. The influence of this high pressure system extends towards the south (Fig. 2b). This results in clear skies and fair weather over the BLLAST site with gentle easterly winds. Higher up in the atmosphere, at $500 \mathrm{hPa}$, a strong ridge extends over the west of Europe (Fig. 2a). This ridge causes a predominantly WNW flow in the upper atmospheric regions above the BLLAST site.

Two soundings of the entire troposphere, taken at a central location in the BLLAST experiment at 10:34 UTC (local time $=\mathrm{UTC}+2$, with $1 \mathrm{~h}$ accounting for daylight saving) and 16:44 UTC, confirm the two regimes with winds sharply turning with height (Fig. 3). In general, the winds during this day are weak in the lower troposphere, not exceeding $6 \mathrm{~m} \mathrm{~s}^{-1}$. Close to the surface, the wind is easterly, but at approximately $1500 \mathrm{~m}$, there is a sharp turning of the wind to WNW. This zone of directional shear remains present during the day, but remains at a height of approximately $1500 \mathrm{~m}$. This is distinctly higher than the maximum boundary layer height during this day, and therefore it can be expected to exert no influence on the boundary-layer dynamics.

On the meso-scale, the proximity of the Pyrenees to the south of the site often leads to a mountain-plain circulation 

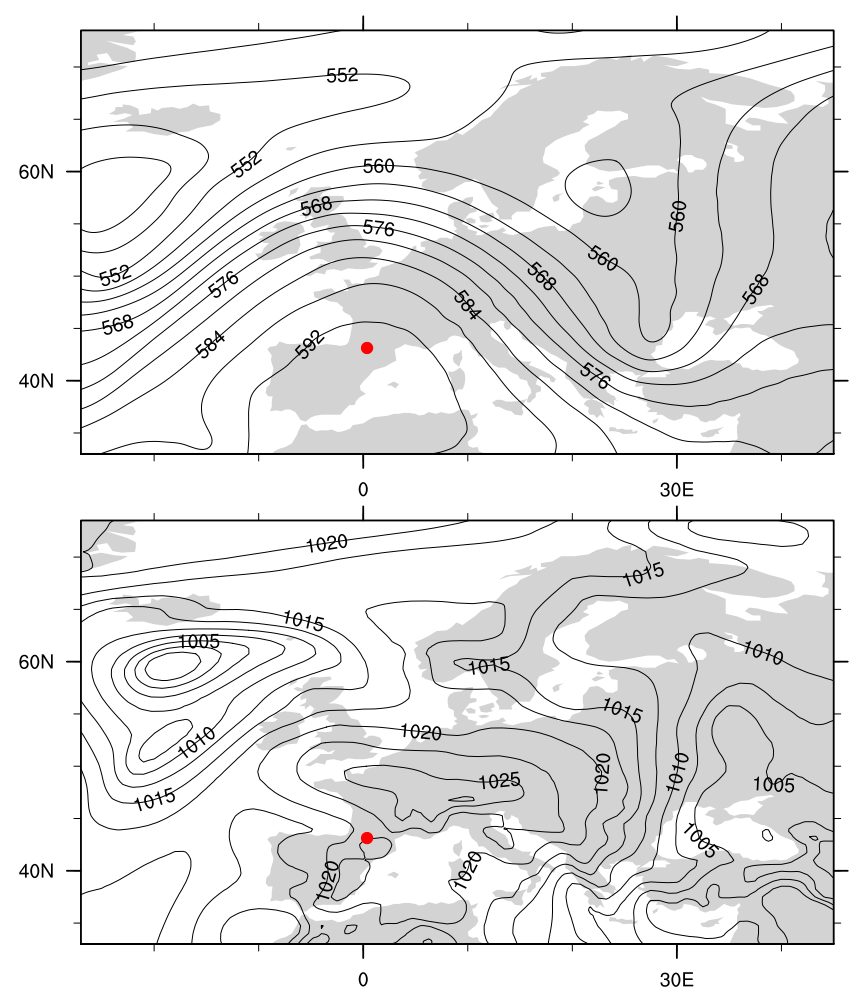

Figure 2. Geopotential height (in decameter) of the $500 \mathrm{hPa}$ level (upper panel) and surface pressure field $(\mathrm{hPa})$ (lower panel) from the reanalysis of ECMWF at 12:00 UTC of the 25 June 2011. The red dot represents the location of the BLLAST experiment.

(Lothon et al., 2014). The behavior of the boundary layer during the day and the general conditions leads us to postulate that large scale forcings such as subsidence and advection should be taken into account to understand the behavior of the boundary layer during the day (see Fig. 1).

25 June 2011 was the second of three consecutive IOPs with fair weather and increasingly warmer temperatures. On this day, the $2 \mathrm{~m}$-temperature rose as high as $28^{\circ} \mathrm{C}$ in the afternoon at the BLLAST site. In the plains to the north of the BLLAST site, temperatures exceeded $30^{\circ} \mathrm{C}$.

\subsection{Case description: surface conditions}

In addition to the nearby complex topography, the BLLAST experiment took place in an area characterized by surface heterogeneity. Figure 4 shows the land-use and the location of the surface flux stations in the vicinity of the main sites. The heterogeneity is characterized by different length scales ranging from 500 to $1000 \mathrm{~m}$. In Fig. 4, the categories represent aggregate land-use types. Especially within the cropland category there is still a large variety. In the BLLAST campaign, turbulent measurements were made above a number of different land-uses, including wheat, grass, maize and natural moor-like vegetation. From this, fluxes are calculated with a uniform processing method (De Coster and Pietersen, 2011).

In Fig. $5 \mathrm{a}$ and $\mathrm{b}$ the radiation budget and surface energy balance of a grass covered site during BLLAST IOP5 is shown (site 2 in Fig. 4). The four components of the radiation show a smooth diurnal cycle with absence of clouds. The averaged Bowen ratio during the day is around 0.3. In conjunction with the initial profiles (not shown), these surface forcings should lead to boundary-layer heights of $\simeq 1100$ m during the afternoon. However, the boundary layer only reached a height of $\simeq 600 \mathrm{~m}$ during this day. This behavior suggests that the development of the boundary layer was influenced by processes besides surface heating and entrainment. To be able to investigate the transition period where weak forcings interact, the development of the daytime boundary layer should be understood first.

The BLLAST campaign took place in a topographically diverse landscape. Although the main site is on a plateau, the height differences in the area are large. Several valleys with a depth of 100-200 m radiate outward to the north of the site. To the south, the foothills of the Pyrenees start and height differences increase. The highest peaks of the Pyrenees, at a distance of $45 \mathrm{~km}$, reach heights of more than $3000 \mathrm{~m}$ a.s.l.

Figure $5 \mathrm{c}$ and $\mathrm{d}$ show the latent and sensible heat flux for the seven stations and the average value for all these stations. All fluxes were computed using the eddy covariance technique, with a sampling rate of at least $10 \mathrm{~Hz}$. These eddycovariance stations were installed at heights lower than $2.5 \mathrm{~m}$ above the surface. Most of the BLLAST characteristic landuses are represented, although the forest site is excluded due to the station height. The 5 min fluxes of each station are shown in blue, the average of these fluxes is indicated with the red crosses in Fig. 5c and d. The fluxes above the different surfaces show a variability of more than $100 \%$ for the sensible heat flux and approximately $50 \%$ for the latent heat fluxes. To represent gradually evolving fluxes and to eliminate effects due to fast changing surface conditions, a sinusoidal function is matched with the average values (dashed black lines). This function is used as the surface boundary condition in the numerical experiments (see Table 1 for the equations).

Here it is important to discuss the role of surface heterogeneity in the CBL dynamics of IOP5. We are aware that two types of heterogeneity can alter the boundary layer dynamics: nonuniform land use properties and topography. Note that in our modeling approach, we take a bottom-up approach in which we reproduce boundary layer dynamics closely constrained by observations. To improve these model results, we externally adjust external the large-scale forcing (subsidence, advection) to better match to the observations of the diurnal variability of CBL growth, potential temperature and specific humidity. In this way, these estimated large-scale forcings integrate the effects of topography and land surface heterogeneity. In relation to the latter, and closer to the boundarylayer scales, previous studies have shown that non-uniform 

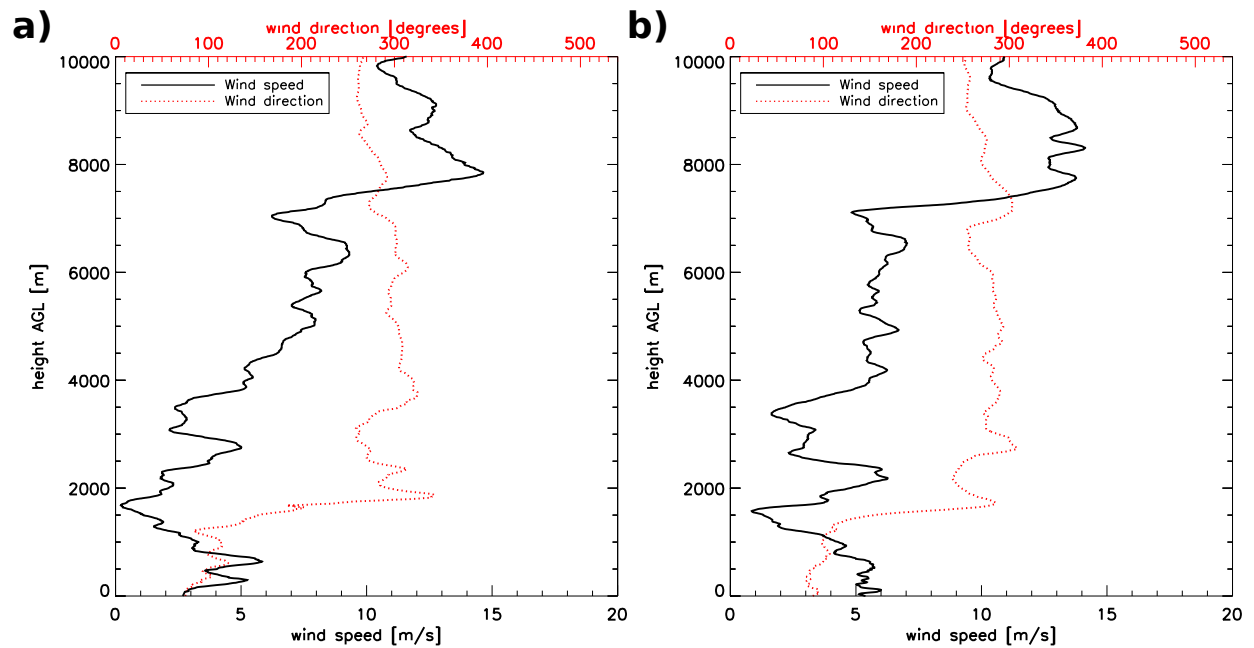

Figure 3. Wind profiles (speed and direction) of the lowest $10 \mathrm{~km}$ of the atmosphere measured by the radiosondes at $25 \mathrm{June} 2011$ : (a) 10:34 UTC and (b) 16:44 UTC.

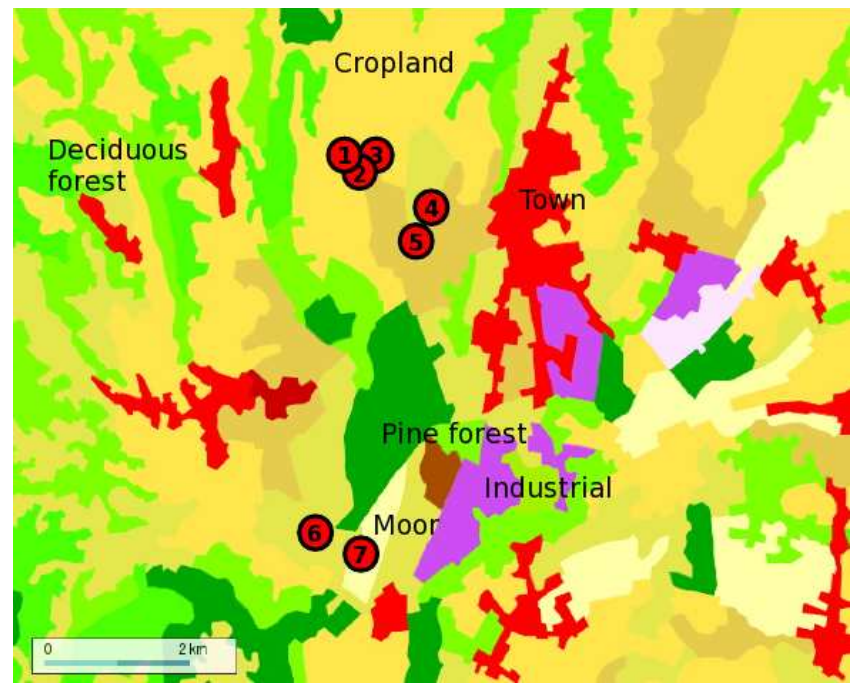

Figure 4. Land use surrounding the BLLAST site and location of the seven surface flux stations used to estimate the sensible and latent heat flux prescribed in the model experiments. The land types are cropland (yellow), deciduous forest (light green), urban (red), pine forest (dark green), industrial (purple) and moor (white).

surface conditions can lead to induced secondary circulations influencing the dynamics of the convective boundary layer (Patton et al., 1997; Maronga and Raasch, 2013; van Heerwaarden et al., 2014). Although there is current debate on the minimal heterogeneity length scale required to trigger secondary circulations, the majority of the studies pointed out that this is approximately $2 z_{i}$, where $z_{i}$ is the boundary layer height. Taking into account that the observed boundary layer height during IOP5 was between 600 and $700 \mathrm{~m}$ and the surface length scales were larger than $1000 \mathrm{~m}$, in our modeling analysis, we will omit the effects of surface heterogeneity in the development of the CBL.

\section{Numerical experiments}

We design a series of numerical experiments to reproduce IOP 5 by means of mixed-layer theory and large-eddy simulation (LES). Our strategy is to use both models to support the data interpretation in order to identify and quantify the main contributors in the development of the boundary layer. In the numerical experiments, the observations of the boundary layer both guide and constrain the models. The mixed-layer model is used to reproduce the observed boundary-layer and the large-scale forcings are inferred from the analysis. Taking the same initial and boundary conditions, we perform systematic experiments with LES to determine the turbulent statistics.

\subsection{Experimental strategy}

The numerical experiments are designed to reproduce the boundary layer of IOP5 as well as possible within the conceptual framework. This means that special attention is paid to the inclusion of all important large scale processes, their magnitude and evolution. The horizontal variation of these large scale contributions are not treated.

First, a conceptual model is used to determine the evolution of the bulk properties of the CBL (van Heerwaarden et al., 2009; Vilà-Guerau de Arellano et al., 2015). Secondly, the Dutch Atmospheric Large-Eddy Simulation (DALES, Heus et al., 2010) is employed to study the case taking advantage of the fact that the most energetic turbulent motions are fully resolved. The initial vertical model profiles of potential temperature $(\theta)$ and specific moisture content $(q)$ are 
a)

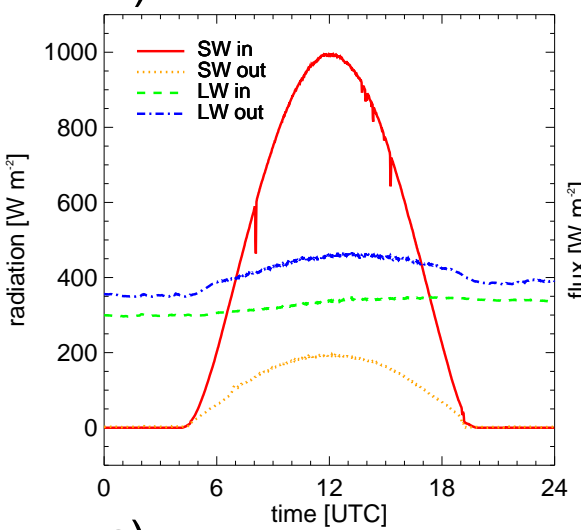

c)

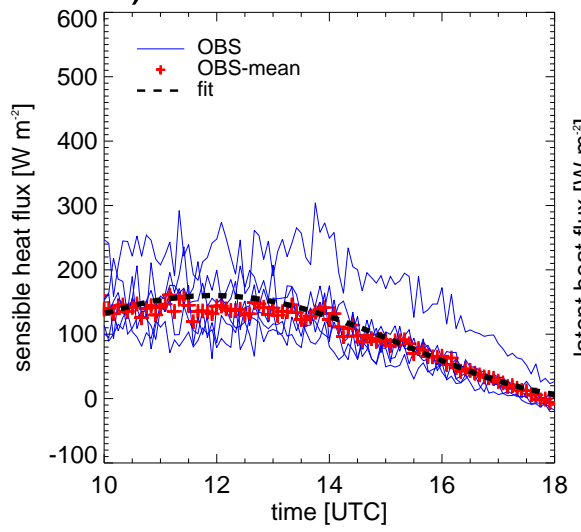

b)

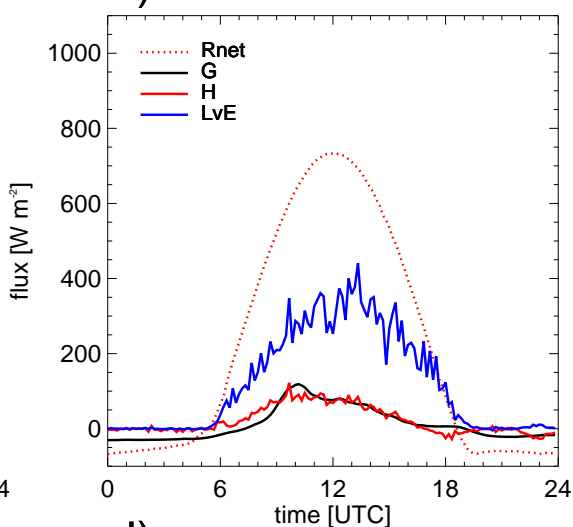

d)

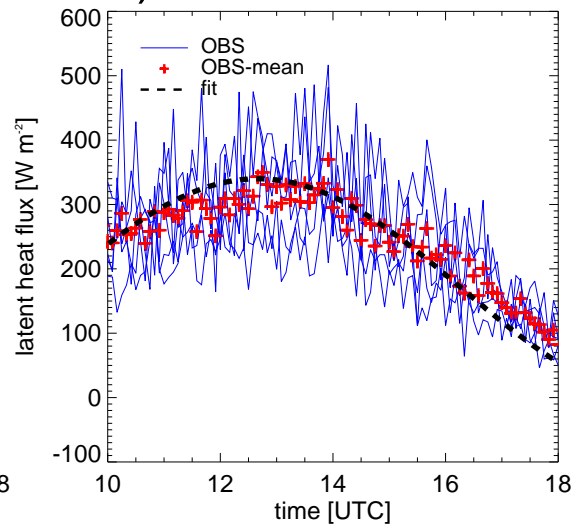

Figure 5. Temporal evolution of (a) the four components of the radiation budget, (b) the components of the surface energy budget, (c) sensible heat flux and (d) latent heat flux taken on 25 June 2011. The radiation and surface energy budget were measured at site 2 , characterized by a footprint influenced by cropland and grass fields. The sensible (c) and latent heat (d) fluxes are from the seven stations shown in Fig. 4. The black dashed line is a fitted curve of the mean of the seven measurements (red crosses) and is used as the surface forcing (sensible and latent heat fluxes) in the numerical experiments.

derived from the early morning soundings. The observations during the day will be used to evaluate the models. The starting point is a simple case, using the initial profiles and surface fluxes from the observations as input (Sect. 5). Subsequently, we will use the observations as a guide to obtain the correct values for subsidence and advection of heat and moisture (Sect. 6).

\subsection{Model description}

In this section, both models are introduced: a mixed-layer model and a large-eddy simulation. The first model is a highly conceptualized model of the boundary layer. The second is a model that explicitly calculates most of the turbulence and gives a detailed picture of the structure of the boundary layer. Combining the two model results, we can unravel and quantify the various contributions to the heat and moisture budgets. Furthermore, we can obtain a detailed overview of the structure of temperature and humidity inside the boundary layer, and we are able to see how the turbulent structures evolve during the day.

\subsubsection{Mixed-layer model}

The mixed-layer model is a bulk model that allows a conceptual representation of the boundary layer. We have included this mixed-layer model to reproduce the essential processes of the CBL prototype. This model uses the boundarylayer thermodynamic equations proposed by Tennekes and Driedonks (1981). The implementation of these equations into the model is similar to van Heerwaarden et al. (2009). The boundary layer is represented as a single model layer and at the entrainment region (top of the CBL), the exchange of heat and specific moisture is parameterized by a jump of the potential temperature and specific moisture over an infinitesimally small height (a 0-order model). The potential temperature and specific humidity in the overlying free troposphere are initialized with a constant lapse rate with height. The use of the mixed-layer equations implies that 
the turbulence inside the boundary layer is not explicitly calculated, and assumes that the potential temperature and the specific humidity are well mixed in the convective boundary layer and constant in height. This assumption is supported by the efficient turbulent mixing under convective conditions. The entrainment flux at the top of the boundary layer $\left(\beta_{\theta_{v}}\right)$ is calculated as a fixed fraction of the buoyancy flux (in our numerical experiments equal to 0.2 ), which means that the entrainment flux is subjected to the same diurnal evolution as the prescribed surface sensible and latent heat flux. An important feature of the model is the possibility to represent subsidence coupled to the entrainment process at the inversion zone and to discriminate how their individual contributions that govern the boundary layer growth. The subsidence velocity is a function of the divergence of the mean horizontal wind and the evolving boundary-layer height. As such, this model enable us to study the balance between subsidence from above and buoyant convection from below, and whether they reach an equilibrium during the CBL development.

\subsubsection{Large-eddy simulation}

The large-eddy-simulation (LES) model that is used is the latest implementation of DALES (Heus et al., 2010). DALES solves the filtered three-dimensional thermodynamic equations, and as a result produces three-dimensional timeevolving fields. In convective boundary layers like the one observed on IOP5, DALES explicitly reproduces approximately $80-90 \%$ of the energy contained by the eddies in the boundary layer. The smaller amounts of turbulent scales are parameterized using a sub-grid scale model that depends on the sub-grid turbulent kinetic energy and is formulated according to Deardorff (1974). DALES gives us a detailed insight in the vertical structure of the boundary layer and enables us to compare measured fluxes inside the boundary layer with simulations, thus giving a detailed quantification of the structure of the boundary layer. In the numerical experiments, we have used a grid of $128^{3}$ with a horizontal resolution of $25 \mathrm{~m}$ and a vertical resolution of $10 \mathrm{~m}$, leading to a domain of $3200 \times 3200 \times 1280 \mathrm{~m}$. The simulation time is $14 \mathrm{~h}$. The subsidence velocity is imposed by a function that is zero at the ground and increases linearly to the CBL top. Above the CBL, the subsidence velocity is constant in height. Similar to the mixed-layer model, the subsidence strength can change over time.

\subsection{Boundary and initial conditions}

Both models, DALES and mixed-layer, use identical initial conditions and surface forcings. The models are initialized with profiles that were derived from the morning soundings of IOP5. The representative surface fluxes from the observations (see Sect. 3.3) are used to provide the lower boundary conditions.
To make sure that the boundary layer is well mixed and that all surface stability has disappeared, the models are not started at sunrise, but at 10:00 UTC. In this way, we ensure that the mixed-layer equations of the mixed-layer model hold. The soundings that were taken during the early morning and at 10:34 UTC were used to construct the initial profiles for both the mixed-layer model and the large-eddy simulation. The boundary-layer height at this time was matched to the estimate made with the UHF radar and the LIDAR (Fig. 6a). In Table 1, the initial conditions for both the mixedlayer model and DALES are listed. As winds were light during IOP5 (see Fig. 3) and we seek to perform a numerical experiment that resembles the prototypical boundary layer, no wind was prescribed in the models.

Two different numerical experiments (cases 1 and 2) are set up to determine the influence of the large scale forcings on the boundary layer during IOP5. In short, these cases are

- Case 1: a boundary layer governed by surface forcings, i.e. a locally driven prototypical boundary layer;

- Case 2: same initial and boundary settings as case 1, except that now we add the contributions of subsidence and advection of heat and moisture, i.e., including contributions of the larger scales.

\section{Case 1: prototypical boundary layer}

The prototype CBL is driven by the surface and entrainment processes. In order to study whether IOP5 follows this classical prototype, we reproduce a situation that is only forced by the surface fluxes, without any other external forcings. This enables us to determine the influence of the surface forcing and it provides us a first indication which large scale influences are of importance. The results are evaluated with surface and upper air observations.

\subsection{Boundary-layer height}

We show the boundary-layer height during IOP5 estimated by ten different methods (eight observational and two based on results obtained employing the mixed-layer model and DALES) in Fig. 6a. Two of the observational methods are based on remote sensing instruments: a vertical UHF radar and an aerosol LIDAR. Other methods to determine the boundary-layer height are based on the profile of virtual potential temperature inside the boundary layer. The maximum gradient of the virtual potential temperature is manually selected as the top of the boundary layer. Three methods rely on profiles made with soundings: two classical radiosondes (manufactured by MODEM and GRAW) and a new method of making frequent radiosoundings developed by Meteo-France (Legain et al., 2013) where the sondes can be retrieved and re-used. Three additional methods are based on profiling by aircraft, one remotely piloted aircraft 
Table 1. Prescribed initial conditions for the numerical experiments using mixed-layer theory and DALES. The conditions correspond at 10:00 UTC at 25 June 2011 at Campistrous (France). $t$ is the time after starting the simulation.

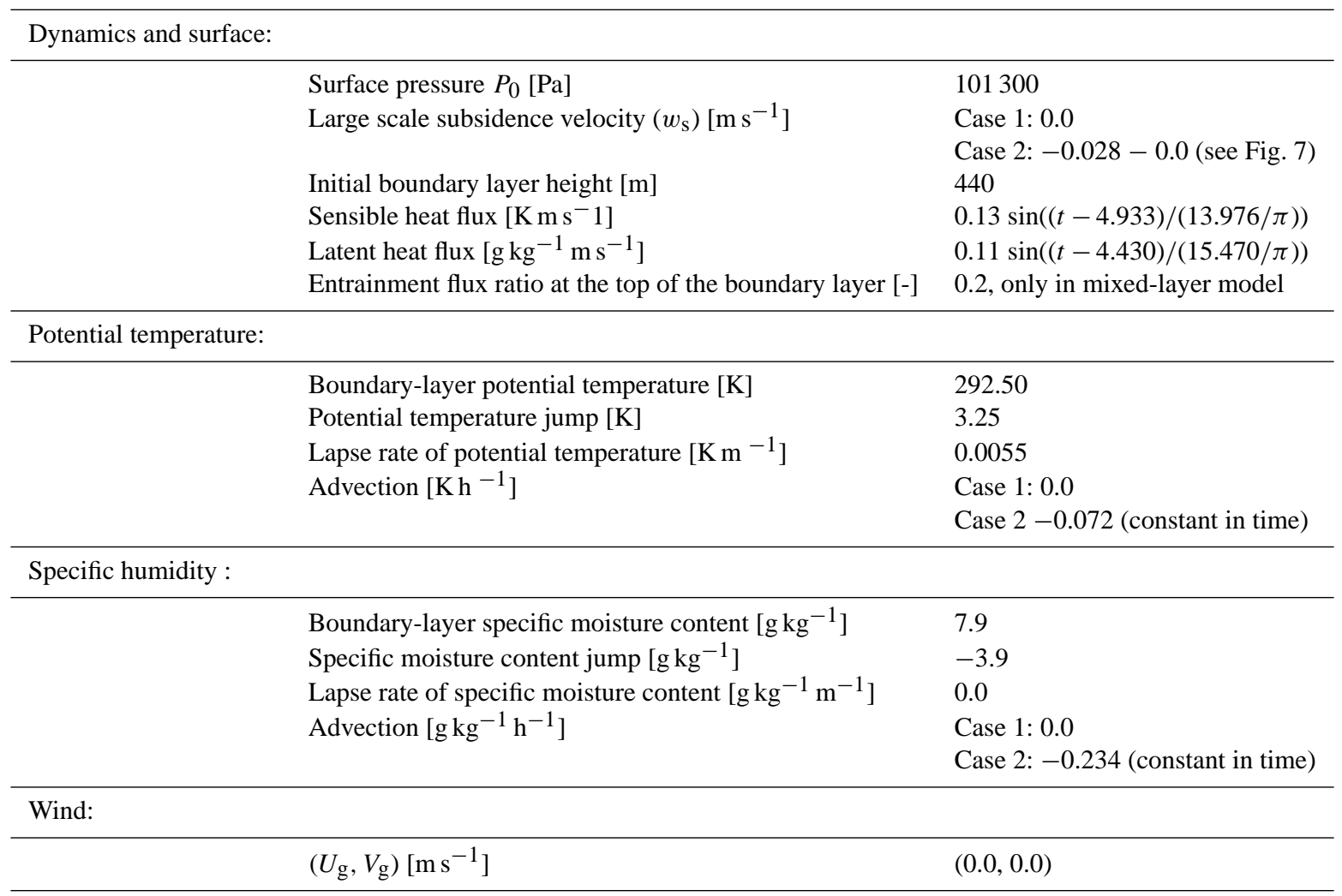

system (the SUMO platform, Reuder et al., 2009) and two manned aircraft (the Sky Arrow operated by IBIMET/CNR and the Piper Aztec operated by SAFIRE). The last two methods to determine the boundary-layer height are based on the interpretation of model results from the mixed-layer model and DALES. The mixed-layer model explicitly calculates the boundary-layer height assuming that this height is equal to the maximum of the potential temperature gradient and the minimum of the buoyancy heat flux. In DALES, the boundary-layer height is diagnosed in the post-processing by assuming that the top of the boundary layer is at the height where the buoyancy flux vertical profile has its largest negative value.

As shown in Fig. 6a, there is a large amount of scatter between different estimates. In analyzing the observations in more detail, we find that, even if we do not take outliers into account, the differences in boundary-layer height can be in the order of $100 \mathrm{~m}$. This number $(\approx 100-200 \mathrm{~m})$ is similar to the depth of the entrainment zone measured by the Lidar. From the observations, we notice that the soundings generally report lower boundary-layer heights than the remote sensing methods, which is to be expected as different physical parameters are used to deduce the boundary-layer height. Not all observation profiles were taken at the same location. A site near stations 4 and 5 (Fig. 4) was used for UHF, LI-
DAR and soundings, the remotely piloted aircraft soundings were taken near stations 6 and 7. The manned aircraft, the Piper Aztec and Sky Arrow, were even further away from the site (up to $20 \mathrm{~km}$ ) because of airspace regulations. Due to the mentioned surface heterogeneity, differences can occur between observations. Most of the soundings are point measurements, whereas the aircraft makes a helical profile, sampling a greater volume of the boundary layer. In Fig. 6a, the observations show a growing CBL until 14:00 UTC. Later in the afternoon, the growth becomes slightly negative. In contrast, the model results show the expected behavior under clear convective conditions driven solely by surface and entrainment processes: a continuous growth, slowing down in the late afternoon (after 16:00 UTC), with the maximum boundary-layer height at the beginning of the evening.

Taking into account the scatter associated with the observations, there is a discrepancy of roughly $400-500 \mathrm{~m}$ between the observations and the results from the numerical experiments. This is a clear indication that processes other than surface heating and entrainment play a role. 


\subsection{Mixed-layer potential temperature and specific humidity}

Figure $6 \mathrm{~b}$ shows model results and observations of the mixed-layer potential temperature and the specific humidity. The sounding values are calculated by taking the average value of the sounding between $100 \mathrm{~m}$ above the ground and $100 \mathrm{~m}$ below the top of the boundary layer. The DALES values are calculated in a similar fashion. The observations at $60 \mathrm{~m}$ height were taken at a tall tower at station 5 (Fig. 4).

The potential temperature observations at $60 \mathrm{~m}$ follow a similar pattern as the profile average observations of the mixed layer for the temperature. Both the mixed-layer model and DALES give a correct representation of the mixed-layer potential temperature, in spite of the large disagreement in the boundary-layer height.

The observations of specific humidity show a lot of scatter between the different instrument platforms. Especially within the mixed-layer moisture observations from the soundings (the triangles in Fig. 6b), the differences are large and can amount up to $1.5 \mathrm{~g} \mathrm{~kg}^{-1}$. Overall, we first observe a slight increase, followed by a gradual decline, probably controlled by the entrainment of dry air. After 15:00 UTC, the specific moisture content starts to rise again. This pattern is the strongest in the tall tower of station 5 (the crosses in Fig. 6b), although on average the soundings also show a slight moistening trend. This could be related to moisture advection in the late afternoon (Couvreaux et al., 2015) or due to surface evaporation that is not being offset by the entrainment of dry air originated at the free troposphere. Although both models show a small amount of drying around noon, it is much less than observed near the surface at the $60 \mathrm{~m}$ tower. The moistening at the end of the afternoon is not yet reproduced by the models. Note that there is a discrepancy between the specific moisture content of the model and the observations of the $60 \mathrm{~m}$-tower at the start of the model run. This is because the initial profiles are based upon soundings of the entire boundary layer. These can differ significantly from the observations at $60 \mathrm{~m}$ height as can be seen in the observations later during the day.

It is relevant to point out here that one would expect slightly lower values of the model results compared to the observations of the specific humidity because of enhanced entrainment of dry air. Model results tend to overestimate the specific humidity above the surface, as shown by Fig. 6b, though the agreement with the more representative averaged bulk values calculated from the radiosounding observations is more satisfactory, in spite of the larger variability. A potential solution is to infer more complicate temporal evolutions of the advection of moisture, but they will have a minor impact on the overall characterization of the boundary layer dynamics during IOP5.

\section{Case 2: including large-scale subsidence and advection}

Case 2 includes the contributions of subsidence motions and large-scale advection of heat and moisture to the development of the atmospheric boundary layer during IOP5. The values and evolution for subsidence and advection of potential temperature and specific humidity were determined by constraining the model results to the observations of boundary layer height and the mixed-layer values of potential temperature and specific moisture. The evolution of subsidence was first adjusted using the observations of the CBL growth gathered by eight different instruments. In a second stage, we use the $\theta$ - and specific humidity evolution to estimate the necessary advection to match the observational evolution of these state variables. The initial- and boundary conditions are listed in Sect. 4.3. The retrieved value and evolution for subsidence velocity are shown in Fig. 7 as well as the values for subsidence calculated using the ECMWF model above the BLLAST observational site characterized by coarse spatial resolution and lower temporal resolution. The contributions of advection of heat and moisture are given between brackets in Table 1. Note that the advection is applied only inside the boundary layer. From Fig. 7, we observe that subsidence velocity has a dependence on time that follows a diurnal evolution with maximum values of $-0.028 \mathrm{~m} \mathrm{~s}^{-1}$ between 13:30 and 14:00 UTC. The values from the ECMWF model are lower and have far less temporal detail than the ones estimated iteratively. Figure 7 indicates that in regions with nearby complex topography it might be required to have estimations of subsidence with higher temporal frequency to properly reproduce the boundary-layer dynamics. This variation on time of the subsidence can be a relevant process in modeling this situation with more complex numerical weather prediction models (Couvreaux et al., 2015).

Together with the subsidence, Fig. 7 shows the resulting values of entrainment velocity for both the mixed-layer model and DALES. The entrainment rate of both models is calculated following Lilly (1968):

$w_{\mathrm{e}}=-\frac{\overline{w^{\prime} \theta_{v_{\mathrm{e}}}^{\prime}}}{\Delta \theta_{v_{z i}}}=\frac{\partial h}{\partial t}-w_{\mathrm{s}}$.

Note that the buoyancy flux at the entrainment zone $\left(-\overline{w^{\prime} \theta_{v_{\mathrm{e}}^{\prime}}}\right)$ is a fixed fraction (0.2) of the prescribed surface buoyancy flux. The potential virtual temperature jump at the boundary layer top $\left(\Delta \theta_{v_{z i}}\right)$ is calculated explicitly whereas the subsidence velocity $\left(w_{\mathrm{s}}\right)$ must be imposed. As Fig. 7 shows, the diurnal evolution of the entrainment is very similar in both models. The overestimation in the mixed-layer results is due to the linear profile of the buoyancy flux assumed in mixed-layer theory that simplifies the curve behavior of the buoyancy flux in the entrainment zone (see Fig. 11).

By analyzing the magnitude of subsidence and entrainment velocities, both are comparable and nearly cancel each 

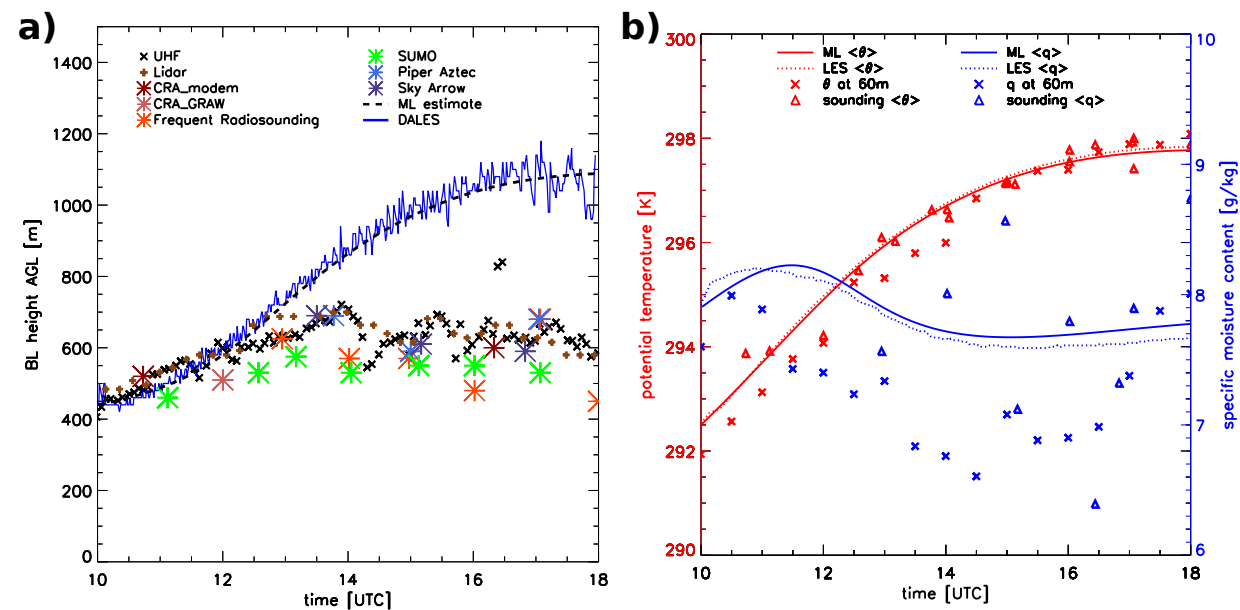

Figure 6. Temporal evolution of (a) boundary-layer height and (b) mixed-layer potential temperature and specific humidity at 25 June 2011 (case 1).

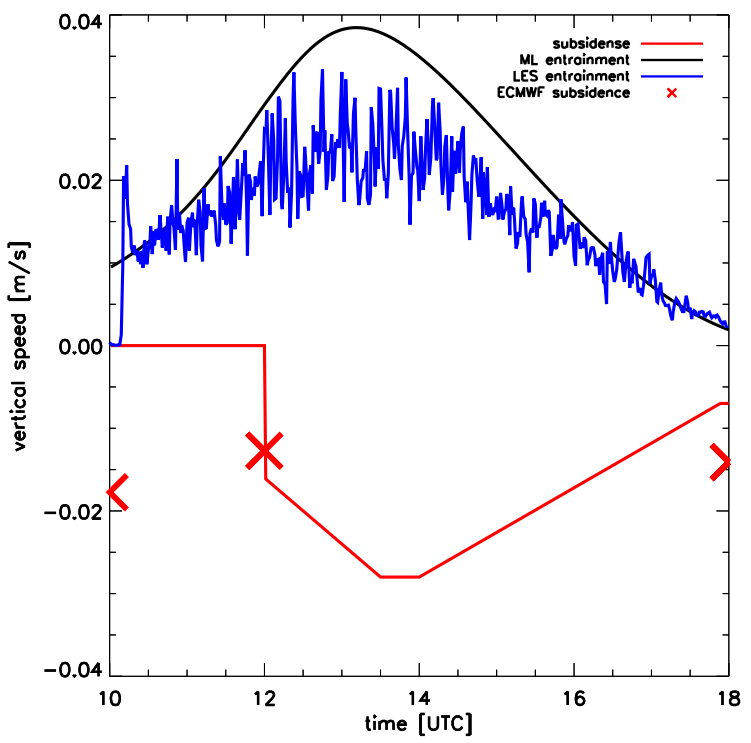

Figure 7. Temporal evolution of the entrainment velocity and prescribed subsidence velocities at the top of the boundary layer for the run with prescribed subsidence (case 2). The subsidence values calculated by ECMWF model are also shown.

other after 12:00 UTC. This is in agreement with the evolution of the observed boundary-layer height that remains almost constant during the afternoon as shown by Eq. (1). Note that the entrainment is mainly driven by the buoyancy heat flux at the surface and has a clear diurnal evolution. The subsidence shows a very similar evolution, thus suggesting the influence of non-local processes that are forced by the diurnal cycle (De Wekker, 2008). An induced circulation such as a mountain circulation could lead to such an evolution of subsidence (see Fig. 1).
In Fig. 8, we show the temporal evolution of the boundarylayer height, the mixed-layer potential temperature and mixed-layer specific humidity. For Case 2, the observations and the models show a satisfactory agreement for boundarylayer height and bulk potential temperature (Fig. 8a). The observations of bulk specific moisture content are more scattered, thus making a comparison between model and observations more difficult. In general, the models calculate a boundary layer height that is slightly overestimated. However, as we will show in Sect. 6.1, the models reproduce the vertical structure of the boundary layer satisfactorily.

The evolution of the mixed-layer potential temperature agrees well with the measurements (Fig. 8b). The moisture content shows a decline in the early afternoon, somewhat later than the observations from the $60 \mathrm{~m}$ tower. The moistening at the end of the afternoon is not represented in the models. This moistening signal comes mainly from the stations near the surface and could be related to moist advection in the late afternoon. However, as the observations show a lot of scatter, this change of moisture advection in time is not included in the simulations. A mesoscale modeling study could give more insight in the evolution of the advection of heat and moisture.

\subsection{Vertical profiles of potential temperature and specific moisture content}

In Fig. 9a we show the vertical potential temperature profiles calculated by the two models and by observations taken at 12:57 UTC. The potential temperature profiles of both models are comparable to the observations. Just above the boundary layer, the observed free troposphere is more stable than higher up. The models however are initialized with a single lapse rate for the entire free troposphere. Comparing the potential temperature jump at the top of the boundary layer, both the sounding and DALES show an entrainment zone 

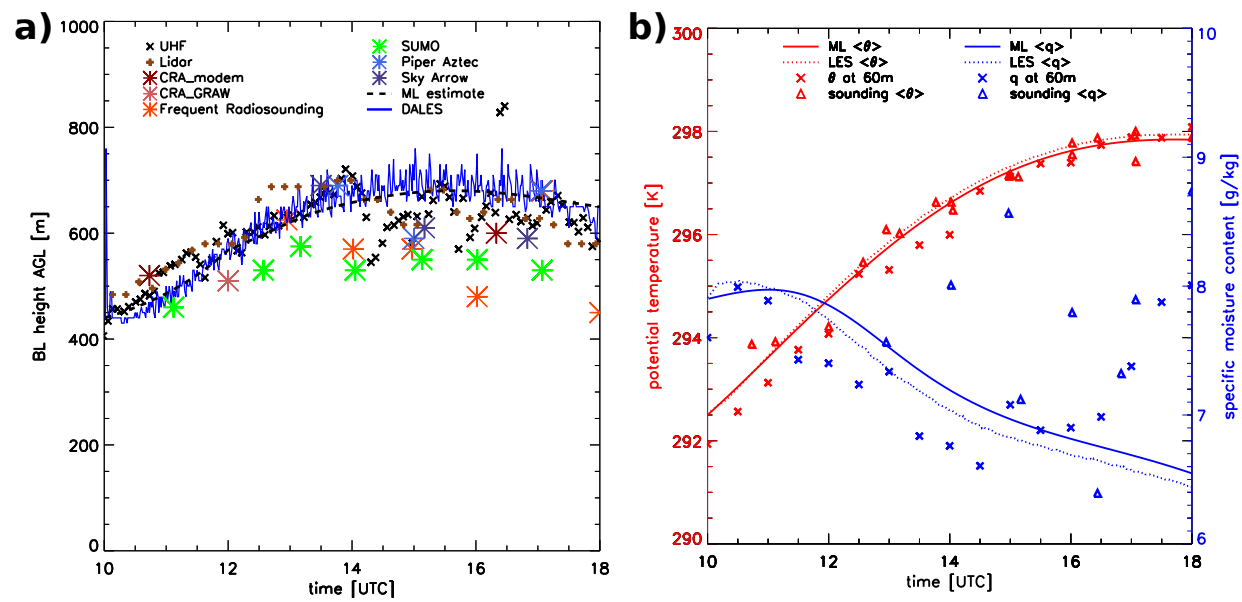

Figure 8. Temporal evolution of (a) boundary-layer height and (b) mixed-layer potential temperature $(\theta)$ and specific humidity $(q)$ on 25 June 2011 (case 2).

with an inversion depth of approximately $100 \mathrm{~m}$. It is also interesting to stress that the observed profile shows a weak stable stratification above $300 \mathrm{~m}$. Two reasons can create this stratification within the well-mixed boundary layer: (a) landsurface heterogeneity (Ouwersloot et al., 2011) and (b) the presence of absorbing aerosols (Barbaro et al., 2013). Our tentative explanation is the following. With respect to (b), aerosol optical depth measurements during BLLAST range between 0.08 and 0.11 . These values can lead to a reduction of the incoming shortwave radiation $\left(\approx 10-20 \mathrm{~W} \mathrm{~m}^{-2}\right)$ (Barbaro et al., 2013) and depending on the aerosol absorbing and scattering characteristics a stabilization of the upper region in the boundary layer. With respect to (a), and although the length scales of surface heterogeneity are smaller than the boundary layer height, the patchy surface around the BLLAST experimental site might induce secondary circulations that are superimposed to the boundary-layer structures. These induced circulations enhance the entrainment of warmer and drier air originating from the free troposphere, stabilizing the upper region of the CBL.

In Fig. $9 b$ the calculated and observed vertical profile of specific moisture at 12:57 UTC are presented. The specific moisture profile is less well mixed with height than the potential temperature profile. Both models compare well with the sounding inside the boundary layer. DALES reproduces the values of specific moisture at the top of the boundary layer and the transition to the free troposphere better than the mixed-layer model. However, both models are approximately $1 \mathrm{~g} \mathrm{~kg}^{-1}$ too dry in the free troposphere. The initial values of specific moisture were matched to the soundings, but there could be moistening of the free troposphere during the day that is not taken into account in the numerical experiments. Similar to the 12:57 UTC potential temperature profile, the specific humidity profile shows microstructures, suggesting a signature of the land surface heterogeneity with drier air in the upper region of the convective boundary layer (between 300 and $600 \mathrm{~m}$ ).

Figure 10 shows the profiles of potential temperature and specific moisture at 16:50 UTC, taken by the Sky Arrow aircraft. These soundings were taken in a helical profile with a sampling frequency of $50 \mathrm{~Hz}$. This profile was made approximately $7 \mathrm{~km}$ southwest of the main site, relatively close to the mountains. The advantage of a helical sounding is that more of the boundary layer is sampled at each level. In this way, the measurements have a larger footprint and in consequence are representative of a larger area. If we compare Figs. 9a and 10a, the profile taken at 16:50 UTC shows more small scale fluctuations. This is partly due to the higher sampling frequency and partly due to the helical profile. Moreover, the profile is characterized by an almost constant value, indicating well mixed conditions. By comparing models and observations at 16:50 UTC, the mixed-layer potential temperature compares well to the observations. For this specific profile, the boundary-layer height is slightly overestimated by the models (see also Fig. 8a). This sounding was taken in close proximity to the Pyrenees $(7 \mathrm{~km}$ southwest of the main site), which means that although the soundings are described in height above ground level, this column of air was higher in an absolute sense. With the specific moisture content taken at 16:50 UTC (Fig. 10b), the signal is even more turbulent than the signal of potential temperature. The mixedlayer averaged specific moisture content is underestimated by $1 \mathrm{~g} \mathrm{~kg}^{-1}$, but the magnitude of the jump of specific moisture at the top of the boundary layer is similar between observations and models. The specific humidity of the free troposphere is underestimated by both models, which could be explained by the moistening trend described for the sounding at 12:57 UTC. 

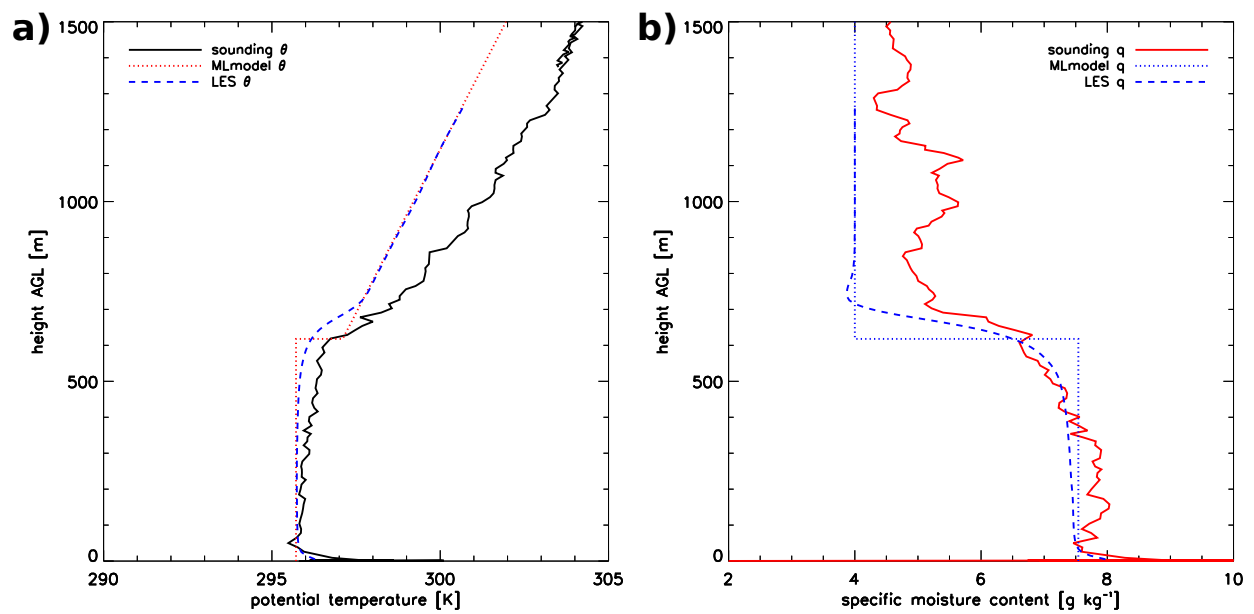

Figure 9. Vertical profile of (a) potential temperature $(\theta)$ and (b) specific humidity $(q)$ at 12:57 UTC: frequent radiosounding, DALES and mixed-layer model.
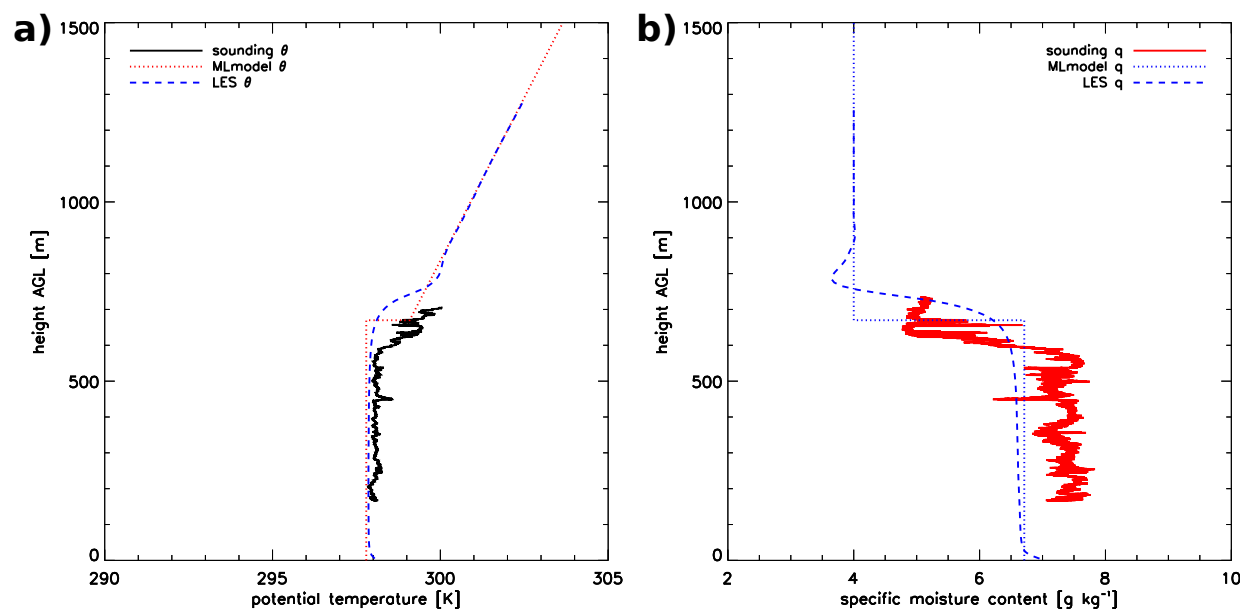

Figure 10. Vertical profile of (a) potential temperature $(\theta)$ and (b) specific humidity $(q)$ at 16:50 UTC: aircraft profiling, DALES and mixedlayer model.

\subsection{Turbulent structure}

Our second aim was to determine whether large-scale forcings exert an influence on the turbulent structure of IOP5 and if this structure is consistent with the prototypical CBL. Therefore, we calculate the higher-order moments of the thermodynamic fluxes and variances from the high frequency aircraft observations and compare them to the DALES calculations. To this end, we employ two observational data sets:

1. turbulent data collected by two aircraft at various heights within the boundary layer;

2. time series of turbulent kinetic energy (TKE) taken at surface flux stations; here, similar to the sensible and latent heat fluxes, we calculate an average TKE from all the stations shown in Fig. 4.
Note that the calculated flux along a flight leg represents an integrated value over a large horizontal distance, thus providing a larger footprint, as opposed to the smaller footprints of the local point measurements of the eddy covariance stations. This enables us to do a more adequate comparison with DALES results that are forced by a horizontally homogeneous surface flux, derived from the average of the flux observations (see Sect. 3.3). The data from the eddy covariance stations is used to study the temporal evolution of the turbulence in the surface layer. We compare this with the vertically integrated TKE using the DALES results. This data set has a high temporal resolution which consequently enables us to describe and explain the decay of turbulence during the late afternoon transition. 


\subsubsection{Vertical profiles of fluxes}

In order to obtain a more detailed understanding of the boundary-layer dynamics, we study the variation with height of the potential temperature and specific humidity fluxes. Between 13:51 and 15:06 UTC, two aircraft: the Sky Arrow and the Piper Aztec gathered high frequency measurements that are compared with the turbulent fluxes calculated using DALES. The observations were made at different levels, and therefore we can make a vertical profile of the second order moments during this hour. Figures 11 and 12 show the vertical profiles of the fluxes of heat and moisture inside the boundary layer. The observations are taken along legs of approximately $40 \mathrm{~km}$ (10-15 min of flight) in an east-west direction. The simulated fluxes from DALES correspond to a 30 min averaged flux for the entire domain from 14:15 until 14:45 UTC (solid line) with dotted lines indicating the minimum and maximum fluxes during the hour at which the observations are taken. Around heights of 525, 625 and $725 \mathrm{~m}$, two legs were flown with different aircraft. Note that these observations were not taken at the same moment.

The profile of the sensible heat flux is shown in Fig. 11. Observations and model are in good agreement. The entrainment zone, where the heat flux is negative, is clearly defined in both observations and the model and shows a good match. The linear decrease from the surface flux to the negative heat flux in the entrainment zone corresponds well between model and observations. It is in this region that there is a countergradient sensible heat flux with positive values for the flux and the potential temperature gradient. The variation of the modeled heat flux at the surface indicates that this period is already in a phase of the day where the heat fluxes decline (Fig. 5c).

Figure 12 shows the observed and modeled latent heat flux vertical profiles. In spite of the imposed (observed, see Sect. 3.3) surface heat fluxes, DALES flux calculations overestimate the aircraft measurements. LeMone et al. (2002) and Górska et al. (2008) have discussed underestimations of the flux measurements taken by aircraft compared to surface point measurements. At the three highest observations, close to the entrainment zone, model and observations compare well, indicating that here the turbulent exchange is modeled correctly. However, inside the boundary layer, the modeled fluxes are roughly twice as high as the observed fluxes. Both model and observations do show latent heat flux profiles that are almost constant with height indicating that the evaporation at the surface is compensated by the drying at the entrainment zone. Consequently, the moisture content inside the boundary layer is in a near steady-state during this period. This is further corroborated by the observations of the specific moisture content near the surface (see the $60 \mathrm{~m}$ observations in Fig. 8b).

In Fig. 13, the non-dimensional buoyancy flux for the same period as Figs. 11 and 12 is shown against the dimensionless height. The buoyancy flux is scaled with the surface buoy-

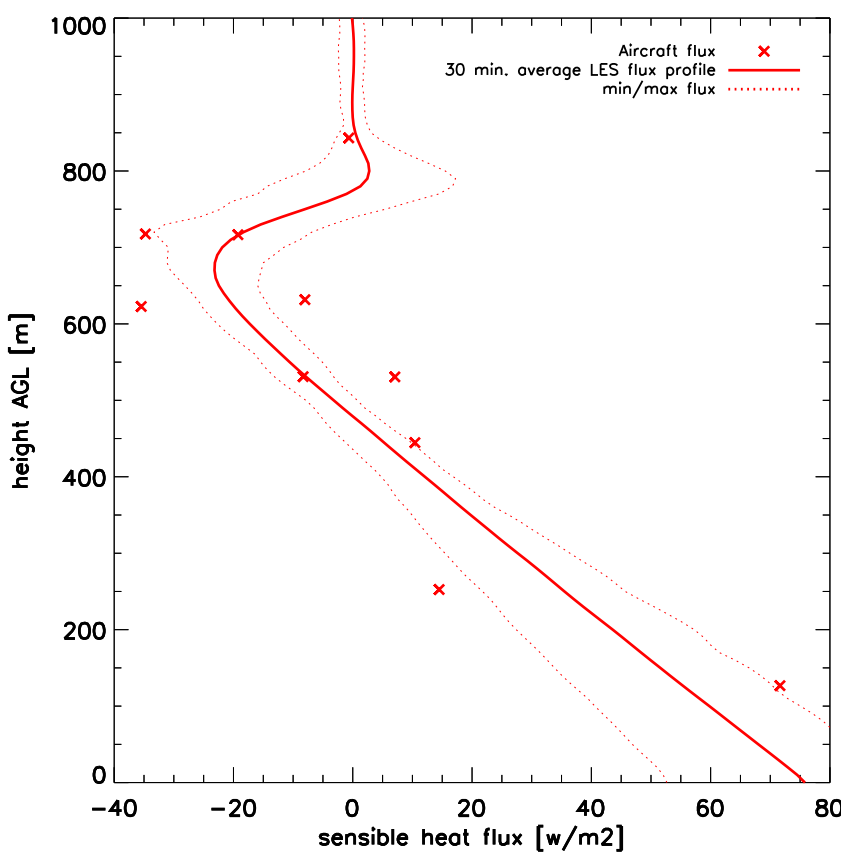

Figure 11. Vertical profile of the sensible heat flux between 14:00 and 15:00 UTC. DALES data correspond to Case 2. Dotted lines indicate the minimum and maximum fluxes calculated by DALES during the hour at which the observations are taken

ancy flux, the height is scaled with the boundary-layer height from the mixed-layer model. Modeled buoyancy fluxes from DALES are shown together with aircraft observations. Because the fluxes are scaled with the surface flux, the spread due to the difference in timing disappears. Overall, the model results match closely with the observations and confirm the notion that the boundary layer for IOP5 behaves similar to the prototypical boundary layer. Model and observations show a clear linear decrease with height in the lower $75 \%$ of the boundary layer. In the top 20-25\% of the boundary layer, the entrainment zone is well defined. The buoyancy flux ra-

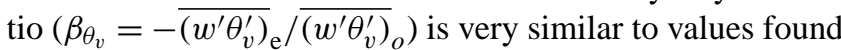
by Davis et al. (1997) and Górska et al. (2008) $\left(\beta_{\theta_{v}} \simeq 0.15\right.$ 0.20 ). The model results are horizontally averaged and the aircraft measurements integrate over a distance of roughly $40 \mathrm{~km}$. All values presented in Fig. 13 are therefore spatially integrated. Local variations may still exist.

\subsubsection{Decay of turbulent kinetic energy}

We complete the study by analyzing a relevant aspect of the afternoon transition extensively studied in more academic LES studies (Nieuwstadt and Brost, 1986; Sorbjan, 1997; Pino et al., 2006; Beare et al., 2006; van Driel and Jonker, 2011): the decay of TKE. This decay plays a key role in the transition from CBL to SBL. We employ the same strategy as before: combining cases 1 and 2 from DALES with surface observations. We show in Fig. 14 how TKE evolves in 


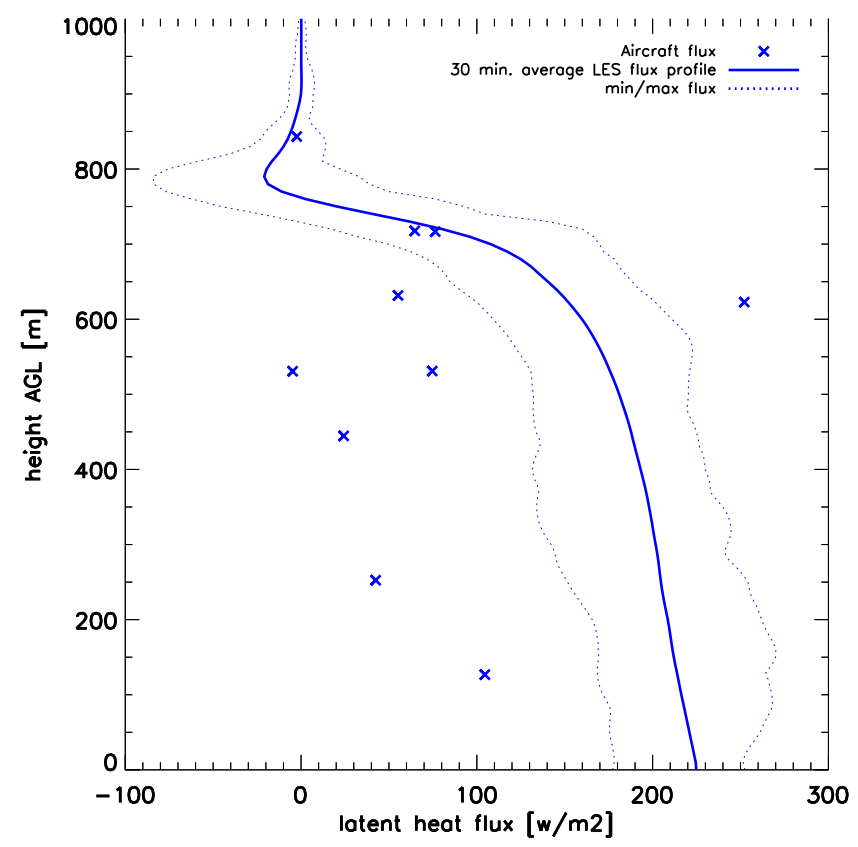

Figure 12. Same as Fig. 11, but now for the latent heat flux.

time from 12:00 to 20:00 UTC. It is important to note that the surface observations are an average of the seven surface stations and that these measurements have been taken 2 or $3 \mathrm{~m}$ above the surface. The TKE calculated by LES represents the lower $10 \%$ of the boundary layer, approximately the first 60-70 $\mathrm{m}$ above the surface. For this calculation, the top of the boundary layer is defined as $30 \mathrm{~m}$ below the level where the buoyancy flux reaches its minimum value. Note that both LES cases are forced without any wind. Observations indicate that the wind was weak during the day $\left(<6 \mathrm{~m} \mathrm{~s}^{-1}\right.$, see Fig. 3). Still, the exclusion of wind in our simulations reduces the amount of TKE that is produced due to the conversion from mean kinetic energy by the shear term.

In Fig. 14, the surface observations show the highest values of TKE whereas Case 2 shows the least. The turbulent fields generated by both DALES simulations show an earlier decay of TKE than the observations, even when we take the lower amount of TKE during the early afternoon into account. Case 2 starts decaying earlier than Case 1. The TKE decay rate of the surface observations is slower than the models in the late afternoon. Even though the buoyancy will be still positive due to the positiveness of the latent heat flux, after 18:00 UTC the sensible heat flux (see Fig. 5b) becomes zero, and the observations show a sharp decline in TKE. To complete this discussion, we refer to the research of the TKE evolution during the afternoon transition conducted by Darbieu et al. (2014) (this special issue) in the whole atmospheric boundary layer. In their study, which focus on another IOP during BLLAST, they found that the TKE decay starts at the higher levels of the boundary layer and with time descends to the surface.

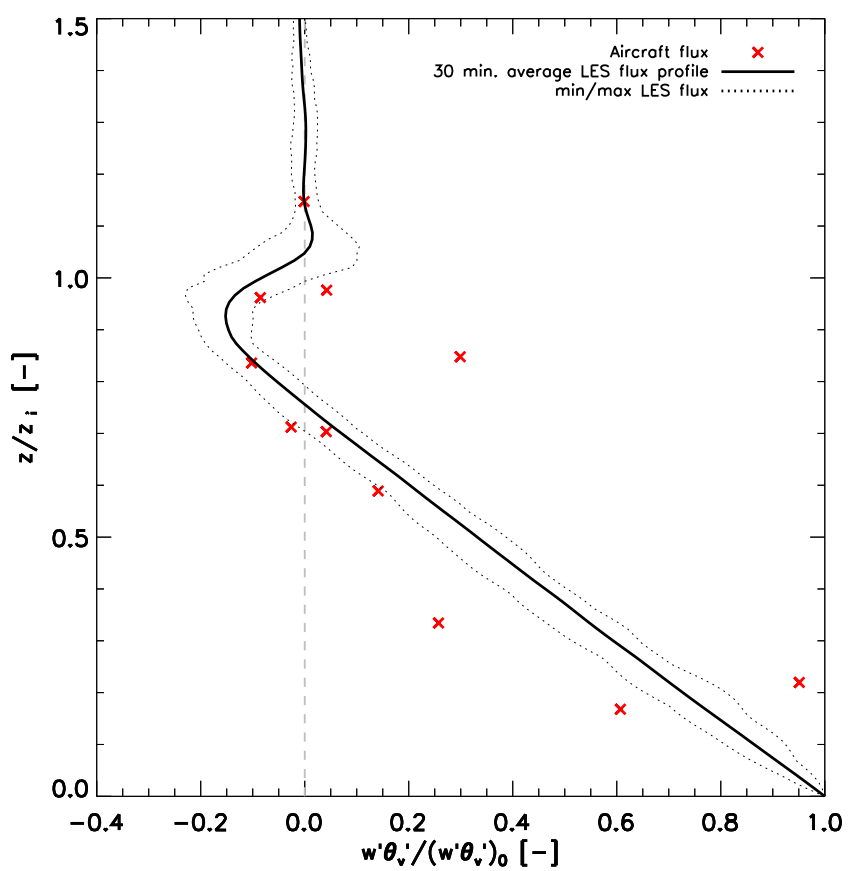

Figure 13. Same as Fig. 11, but now for the non-dimensional buoyancy flux and height.

The difference between cases 1 and 2 is explained by the fact case 1 is characterized by much more vigorous growth during the afternoon, with the boundary layer becoming much deeper, enabling the formation of larger length scales. Case 2, which includes subsidence and advection (see the method to estimate these two forcing at the beginning of Sect. 6), has a much more suppressed growth, limiting the growth and size of the largest eddies. Therefore, the turbulent motions also become more suppressed. That means that if we take large scale forcings into account, the levels of TKE become lower and the decay of TKE starts slightly earlier.

We made Fig. 14b by scaling the TKE evolution using the convective velocity $\left(w_{*}\right)$ and the moment of maximum sensible heat flux, and the time with the eddy turnover time $\left(t_{*}=z_{i} / w_{*}\right)$, similar to Nieuwstadt and Brost (1986). Employed scales are $t_{0}=11: 55 \mathrm{UTC}, t_{*}=0.1172 \mathrm{~h}$ (approximately $7 \mathrm{~min}$ ) and $w_{*}=1.457 \mathrm{~m} \mathrm{~s}^{-1}$. Here, we observe the earlier decay of case 2 more clearly, although the difference remains fairly small. Both model runs show lower levels of TKE than the surface observations. Other factors that might lead to lower levels of TKE are the exclusion of wind in the models (absence of the contribution of shear to maintain TKE) and local secondary circulations due to surface heterogeneity, as suggested in Sect. 6.1. Our final explanation in analyzing the modeled TKE evolution is that the largest turbulent scales in case 1 maintain larger levels of turbulence, slightly delaying the decay process. 

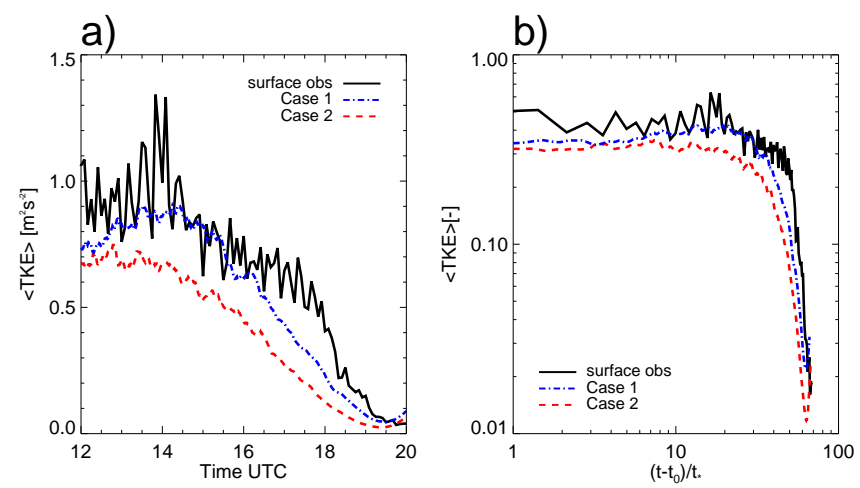

Figure 14. Temporal evolution of TKE in the boundary layer. Left panel: surface measurements and DALES experiment cases 1 and 2 . Right panel: non-dimensional measurements and DALES results.

\section{Conclusions}

We find quantitative evidence that subsidence motions and the large-scale advection of heat and moisture are key contributions to the heat and moisture budgets of the atmospheric boundary layer observed during the BLLAST experiment. Focusing on IOP5, we quantify these two contributions in a numerical experiment forced by surface observations and resulting entrainment to describe the diurnal evolution of the budget of heat and moisture. We intensively employ vertical radiosoundings and remote sensing observations combined with large-eddy simulation and mixed-layer theory to determine and discuss the boundary-layer height using eight different measurement techniques.

The systematic numerical experiments enable us to break down the various components of the heat and moisture budget that determine the boundary-layer height evolution. As a result, we find that by only taking surface and entrainment fluxes into account, we overestimate the boundarylayer depth by $70 \%$. Constraining our numerical experiments with the observations of the boundary-layer depth and bulk quantities, we are able to quantify the magnitude and temporal evolution of subsidence and advection. The subsidence velocity shows a diurnal evolution and is slightly larger in magnitude than the values found with the ECMWF model (with lower spatial and temporal resolution). This diurnal evolution of subsidence suggests the influence of processes that are governed by the diurnal heating cycle, such as a mountain circulation. When these large-scale forcings are included, LES and mixed-layer model represent the evolution of the state variables and the turbulent statistics (LES).

In analyzing the potential temperature flux vertical profile, we find a good agreement between the measurements and large-eddy simulations. This reinforces that BLLAST boundary layers follow the CBL prototype, provided the adequate estimation of large-scale forcings. For the moisture vertical profile, the discrepancy between models and observations is larger, but both yield similar values of the ratio between entrainment- (drying) and surface flux (evaporation). Especially at the end of the afternoon, when observations show a rise in specific moisture content, models and observations diverge. For TKE, we do find a fast decay rate around the time the sensible heat flux becomes zero. The large-eddy simulations show a more gradual decline. Even though the largescale forcings do not directly disturb the turbulent vertical structure, we find that the numerical simulation, including subsidence and advection is characterized by smaller turbulent kinetic energy and starts to decay earlier than the simulation only driven by surface and entrainment processes. This is mainly due to the shallower and weaker large turbulent eddies limited by the atmospheric boundary layer growth. Therefore, we recommend adequately identifying the largescale forcings in studying the afternoon decay.

Finally, we advocate the use of our approach to estimate the contributions of subsidence and horizontal advection of heat and moisture. The combination of observations and mixed-layer theory can be very useful in the interpretation of the observed heat and moisture budget, yielding complementary data to the estimations given by numerical weather forecast models. The approach proposed here can be applied to other cases with sufficient observational density and can be of particular use for the other IOPs of the BLLAST campaign. Two major advantages of our proposed method are the higher temporal resolution and that the modeling is done at a scale close to the surface- and boundary-layer observations. This enables us to carry out in-depth studies of the diurnal evolution, as opposed to ECMWF model output that provides output at a lower spatial and temporal evolution. In relation to the validity of the prototypical CBL, the results obtained here with the mixed-layer model ensure that the canonical CBL is still a valid representation of the diurnal atmospheric boundary layer and afternoon transition, provided that the large-scale influences are properly quantified, considering their large influence on the budgets of heat and moisture.

Acknowledgements. BLLAST field experiment was made possible thanks to the contributions of several institutions and supports: INSU-CNRS (Institute National des Sciences de l'Univers, Centre National de la Recherche Scientifique, LEFE-IDAO program), Météo France, Observatoire Midi-Pyrénées (University of Toulouse), EUFAR (EUropean Facility for Airborne Research) and COST ES0802 (European Cooperation in the field of Science and Technology). The field experiment would not have occurred without the contribution of all participating European and American research groups, which all have contributed in a significant amount (see http://bllast.sedoo.fr/supports/). BLLAST field experiment was hosted by the instrumental site of Centre des Recherches Atmosphérique, Lannemezan, France (Observatoire Midi-Pyrénées, Laboratoire d'Aérologie). BLLAST data are managed by SEDOO, from Observatoire Midi-Pirénées. One eddy covariance station was supported by the Meteorology and Air Quality Section at Wageningen University and two eddy covariance stations were supported by the University of Bonn and DFG 
project SCHU2350/21. The large-eddy simulations were made possible thanks to the financial support of the Dutch Research Council (NWO) (SH-060-13 and SH-312-14). We are grateful to Wayne Angevine (NOAA-ESRL,USA) for his insight comments in an early version of the manuscript. Van Gogh grant given by NUFICC and French-Dutch Academy has supported the traveling to Lannemezan of Jordi Vilà.

Edited by: E. Pardyjak

\section{References}

Barbaro, E., Vilà-Guerau de Arellano, J., Krol, M. C., and Holtslag, A. A. M.: Impacts of Aerosol Shortwave Radiation Absorption on the Dynamics of an Idealized Convective Atmospheric Boundary Layer, Bound.-Lay. Meteorol., 148, 31-49, 2013.

Basu, S., Vinuesa, J. F., and Swift, A.: Dynamic LES modeling of a diurnal cycle, J. Appl. Meteor. Climat., 47, 1496-1516, 2008.

Beare, R. J., Edwards, J. M., and Lapworth, A. J.: Simulation of the observed evening transition and nocturnal boundary layer: Large-eddy simulation, Q. J. Roy. Meteorol. Soci., 132, 81-99, 2006.

Conzemius, R. J. and Fedorovich, E.: A Case Study of Convective Boundary Layer Development during IHOP2002: Numerical Simulations Compared to Observations, Mon. Weather Rev., 136, 2305-2320, 2008.

Couvreaux, F., Canut, G., Bazile, E., Seity, Y., Lothon, M., Lohou, F., Pietersen, H., and Legain, D.: Representation of the afternoon transition in numerical weather prediction modles: evaluation with BLLAST data, Atmos. Chem. Phys. Discuss., in preparation, 2015.

Darbieu, C., Lohou, F., Lothon, M., Vilà-Guerau de Arellano, J., Couvreux, F., Durand, P., Pino, D., Patton, G. E., Nilsson, E., Blay-Carreras, E., and Gioli, B.: Turbulence vertical structure of the boundary layer during the afternoon transition, Atmos. Chem. Phys. Discuss., 14, 32491-32533, doi:10.5194/acpd-1432491-2014, 2014.

Davis, K. J., Lenschow, D. H., Oncley, S. P., Kiemle, C., Ehret, G., Giez, A., and Mann, J.: Role of entrainment in surfaceatmosphere interactions over the boreal forest, J. Geophys. Res., 102, 219-230, 1997.

Deardorff, J. W.: Three-dimensional numerical study of the height and mean structure of a heated planetary boundary layer, Bound.Lay. Meteorol., 7, 81-106, 1974.

De Coster, O. M. Y. and Pietersen, H. P.: BLLAST - uniform processing of Eddy-Covariance data, Internship Report Meteorology and Climatology, Wageningen University and Research Center, 2011.

De Wekker, S.: Observational and numerical evidence of depressed convective boundary layer heights near a mountain base, J. Appl. Meteorol. Climatol., 47, 1017-1026, 2008.

Edwards, J. M., Basu, S., Bosveld, F. C., and Holtslag, A. A. M.: The impact of radiation on the GABLES3 large-eddy simulation through the night and the morning transition, Bound.-Lay. Meteorol., 152, 189-211, 2014.

Garratt, J. R. and Brost, R. A.: Radiative cooling effects within and above the nocturnal boundary layer, J. Atmos. Sci., 38, 27302746, 1981.
Górska, M., Vilà-Guerau de Arellano, J., LeMone, M. A., and van Heerwaarden, C. C.: Mean and Flux Horizontal Variability of Virtual Potential Temperature, Moisture, and Carbon Dioxide: Aircraft Observations and LES Study, Mon. Weather Rev., 136, 4435-4451, 2008.

Heus, T., van Heerwaarden, C. C., Jonker, H. J. J., Pier Siebesma, A., Axelsen, S., van den Dries, K., Geoffroy, O., Moene, A. F., Pino, D., de Roode, S. R., and Vilà-Guerau de Arellano, J.: Formulation of the Dutch Atmospheric Large-Eddy Simulation (DALES) and overview of its applications, Geosci. Model Dev., 3, 415-444, doi:10.5194/gmd-3-415-2010, 2010.

Kumar, V., Svensson, G., Holtslag, A. A. M., Meneveau, C., and Parlange, M. B.: Impact on surface flux formulations and geostrophic forcing on large-eddy simulations of diurnal atmospheric boundary layer, J. Appl. Meteor. Clim., 49, 1496-1516, 2010.

Legain, D., Bousquet, O., Douffet, T., Tzanos, D., Moulin, E., Barrie, J., and Renard, J.-B.: High-frequency boundary layer profiling with reusable radiosondes, Atmos. Meas. Tech., 6, 21952205, doi:10.5194/amt-6-2195-2013, 2013.

LeMone, M., Grossman, R., Mcmillen, R., Liou, K.-N., Ou, S., Mckeen, S., Angevine, W., Ikeda, K., and Chen, F.: Cases-97: latemorning warming and moistening of the convective boundary layer over the walnut river watershed, Bound.-Lay. Meteorol., 104, 1-52, 2002.

Lilly, D.: Models of cloud-topped mixed layers under a strong inversion, Q. J. Roy. Meteorol. Soc., 94, 292-309, 1968.

Lothon, M., Lohou, F., Pino, D., Couvreux, F., Pardyjak, E. R., Reuder, J., Vilà-Guerau de Arellano, J., Durand, P, Hartogensis, O., Legain, D., Augustin, P., Gioli, B., Lenschow, D. H., Faloona, I., Yagüe, C., Alexander, D. C., Angevine, W. M., Bargain, E, Barrié, J., Bazile, E., Bezombes, Y., Blay-Carreras, E., van de Boer, A., Boichard, J. L., Bourdon, A., Butet, A., Campistron, B., de Coster, O., Cuxart, J., Dabas, A., Darbieu, C., Deboudt, K., Delbarre, H., Derrien, S., Flament, P., Fourmentin, M., Garai, A., Gibert, F., Graf, A., Groebner, J., Guichard, F., Jiménez, M. A., Jonassen, M., van den Kroonenberg, A., Magliulo, V., Martin, S., Martinez, D., Mastrorillo, L., Moene, A. F., Molinos, F., Moulin, E., Pietersen, H. P., Piguet, B., Pique, E., RománCascón, C., Rufin-Soler, C., Saïd, F., Sastre-Marugán, M., Seity, Y., Steeneveld, G. J., Toscano, P., Traullé, O., Tzanos, D., Wacker, S., Wildmann, N., and Zaldei, A.: The BLLAST field experiment: Boundary-Layer Late Afternoon and Sunset Turbulence, Atmos. Chem. Phys., 14, 10931-10960, doi:10.5194/acp14-10931-2014, 2014.

Maronga, B. and Raasch, S.: Large-eddy simulations of surface heterogeneity effects on the convective boundary layer during the LITFASS-2003 experiment, Bound.-Lay. Meteorol., 146, 17-44, 2013.

Nieuwstadt, F. T. M. and Brost, R. A.: The decay of convective turbulence, J. Atmos. Sci., 43, 532-546, 1986.

Ouwersloot, H. G., Vilà-Guerau de Arellano, J., van Heerwaarden, C. C., Ganzeveld, L. N., Krol, M. C., and Lelieveld, J.: On the segregation of chemical species in a clear boundary layer over heterogeneous land surfaces, Atmos. Chem. Phys., 11, 1068110704, doi:10.5194/acp-11-10681-2011, 2011.

Patton, E. G., Sullivan, P. P., and Moeng, C. H.: Observed Lagrangian Transition of Stratocumulus into Cumulus during AS- 
TEX: Mean State and Turbulence Structure, J. Atmos. Sci., 54 2157-2173, 1997.

Pino, D., Jonker, H. J. J., Vilà-Guerau de Arellano, J., and Dosio, A.: Role of shear and the inversion strength during sunset turbulence over land: characteristic length scales, Bound.-Lay. Meteorol., 121, 501-515, 2006.

Reuder, J., Brisset, P., Jonassen, M., Müller, M., and Mayer, S.: The Small Unmanned Meteorological Observer SUMO: A new tool for atmospheric boundary layer research, Meteorol. Z., 18, 141$147,2009$.

Sorbjan, Z.: Decay of convective turbulence revisited, Bound.-Lay. Meteorol., 82, 501-515, 1997.

Stensrud, D.: Elevated residual layers and their influence on surface boundary-layer evolution, J. Atmos. Sci., 50, 2284-2293, 1993.

Stevens, B., Moeng, C.-H., Ackerman, A., Bretherton, C. S., Chond, A., de Roode, S., Edwards, J., Golaz, J.-C., Jiang, H., Khairoutdinov, M., Lirkpatrick, M. P., Lewellen, D. C., Lock, A., Müller, F., Stevens, D. E., Whelan, E., and Zhu, P.: Evaluation of large-eddy simulations via observations of nocturnal marine stratocumulus, Mon. Weather Rev., 133, 1443-1462, 2005.
Stull, R. B.: Meteorology for Scientists and Engineers, 2nd Edn., Cengage Learning Services, 2000.

Tennekes, H. and Driedonks, A. G. M.: Basic entrainment equations for the atmospheric boundary layer, Bound.-Lay. Meteorol., 20, 515-531, 1981.

van Driel, R. and Jonker, H. J.: Convective boundary layers driven by nonstationary surface heat fluxes, J. Atmos. Sci., 68, 727-738, 2011.

van Heerwaarden, C. C., Vilà -Guerau de Arellano, J., Moene, A. F., and Holtslag, A. A. M.: Interactions between dry-air entrainment, surface evaporation and convective boundary-layer development, Q. J. Roy. Meteorol. Soc., 1291, 1277-1291, 2009.

van Heerwaarden, C. C., Mellado, J. P., and DeLozar, A.: Scaling laws for the heterogeneously heated free convective boundary layer, J. Atmos. Sci., 71, 3975-4000, 2014.

Vilà-Guerau de Arellano, J., van Heerwaarden, C. C., van Stratum, B. J. H., and van den Dries, K.: Atmospheric boundary layer: Integrating chemistry and land interactions, Cambridge University Press, 2015. 